\title{
Reflux in Germany: Results of a Survey
}

\author{
Thomas Wilke ${ }^{*}, 1$ and Joachim Winkler ${ }^{2}$ \\ ${ }^{1} I P A M / H o c h s c h u l e$ Wismar, Germany \\ ${ }^{2}$ Hochschule Wismar, Germany
}

\begin{abstract}
Background: The aim of this study, conducted over a period of two weeks in summer 2006, was to collect representative data about reflux in Germany.

Methods: 1,892 persons in five German cities and the Federal city-state of Berlin were questioned about the frequency and severity of their reflux symptoms, and what treatments they had opted for. Moreover, this study collected data about sociodemographic and socioeconomic status of the respondents. So the relationship between this status and the prevalence of reflux symptoms and individual treatment decisions could be analyzed.
\end{abstract}

Results: Approximately 50\% of the interviewees had personally experienced typical reflux symptoms. Approximately $21 \%$ of the sample had suffered from these symptoms during the 4 weeks prior to the survey. Typical sociodemographic factors such as gender and socioeconomic factors such as social status explain neither the appearance nor the severity of reflux symptoms; age alone exerts a small positive influence on both variables. Approximately $80 \%$ of the interviewees with acute reflux treated their symptoms; dominant choices in this context are dieting, self-medication with OTC drugs, and the consultation of medical experts.

Conclusions: Comparing results of this survey with earlier data, reflux prevalence in Germany is rising. Mostly, acutely ill patients treat their symptoms. Surprisingly, socioeconomic status plays no role in explaining treatment decisions of patients.

Keywords: Reflux, heartburn, GERD.

\section{INTRODUCTION}

Reflux symptoms rank among the most frequently treated ailments in out-patient departments. Existing surveys conclude that between $20 \%$ and $51 \%$ of the adult population suffers from typical, physiologically noticeable symptoms like heartburn or acid regurgitation [1-16]. Reflux results in a significant decline in the quality of life, and is responsible for the consumption of a sizeable portion of available health care resources [17-19]. In addition, several investigations show that reflux is a growing concern in industrialized countries [20, 21].

Certain epidemiological data concerning the frequency of reflux and/or GERD in Germany exist. Four studies deal with this topic. A telephone poll of 1,000 randomly chosen persons in 2001 concluded that approximately $28 \%$ of the population suffers from reflux symptoms [22]. A second survey, analyzing the patients of a general practitioner, showed that $51 \%$ of them could be characterized as GERD patients [23]. Moreover, a third population-based survey of 268 residents of one city (Cologne) concluded that about one-third of the Cologne adult population suffers from reflux [24]. Data from a nationwide survey show a reflux prevalence of $43 \%$. However, a comparatively low prevalence of

*Address correspondence to this author at the Institute for Pharmacoeconomics and Drug Logistics (www.ipam-wismar.de), University of Wismar, PF 1210, D-23952 Wismar, Germany; Tel: 0049-3841-753-504; Fax: 0049-3841-753-131; E-mail: thomas.wilke@hs-wismar.de moderate and severe reflux symptoms (14\% and 4\%, respectively) was found [25].

This paper illustrates the results of a survey accomplished in the summer of 2006. Specifically, this survey aims to answer the following questions:

1. How often, and with what intensity, does reflux occur in the German population?

2. Are there any general socio-demographic factors which explain the appearance of reflux and/or the severity of its symptoms?

3. What treatment decisions do the patients make? Do these treatment decisions depend on certain factors like socioeconomic status or health insurance?

\section{MATERIAL AND METHODS}

The survey was conducted from May 29th 2006 to June 9th 2006 by 38 educated interviewers. Nineteen teams (each composed of two members, both of whom carried out the interviews) interviewed 1,892 persons face-to-face using a standardised questionnaire (Appendix A).

People were interviewed in five northern German cities (Wismar, Lübeck, Rostock, Schwerin, and Hamburg), and in Berlin, where there were 100 respondents (Appendix B). Interviewed persons were chosen randomly "on the street". In order to minimize the interviewer-related "selection bias", specific guidelines regarding the composition of the sample were issued to each of the interviewing teams as follows: 
- $\quad$ Gender: the sexes were to be equally represented.

- $\quad$ Age: following the distribution of age in the official statistics, each of the interviewing teams was instructed to ensure that $20 \%$ of the persons interviewed were between 20 and $30,52 \%$ between 31 and 60 , and $28 \%$ over 60 years old [26].

- $\quad$ Social status: $50 \%$ of the persons were to live in a city district with an above-average standard of living and $50 \%$ in a city district with a below-average standard of living. These districts were identified in each town before the survey began.

The structure of the sample shows that the abovementioned guidelines were completely adhered to (Table 1):

- Very close to $50 \%$ of the respondents are male and female, respectively.

- $\quad$ The age structure of the sample approximates that of the German population.

- In order to demonstrate social status, the Winkler Social Status Index was calculated for each person interviewed [27]. This index is based on three factors: education, profession, and net income per household. However, 406 of the respondents $(21 \%)$ did not answer the question about their net household income. Consequently, the social status index for this subgroup was calculated on the basis of education and profession alone. Several investigations show that this is generally a very reliable and validated method to derive the social state index [27].

- $\quad$ The proportion of persons covered by either compulsory or private health insurance corresponds very well to the known nationwide figures [28]. Only the proportion of compulsorily insured persons with an additional private insurance found during the survey is well below the known national average; a reason may be that some of the interviewees did not know their insurance status (concerning additional insurances covering some details of health insurance) in detail. This is because most of the additional private health care insurance contracts only cover hospital costs.

- $\quad$ The sample cannot be called representative in every respect. People were only interviewed in six German cities. The population in other urban complexes and the rural areas are likely to be underrepresented. If re- flux should prove to be a geographical phenomenon even in a nation-wide analysis, a bias of the survey results cannot be excluded.

Nevertheless, taking the aim of this survey into account, the sample of the 1,892 persons can be characterized as sufficiently representative. In detail, distribution of important socio-demographic factors like age, gender, social status and type of health care insurance established in the survey correspond to the averages in the population in Germany. Therefore, this sample establishes representative epidemiological reflux data, which are definitely superior to those found in most pre-existing studies. However, it must be pointed out that questions in the survey referred only to typical refluxsymptoms like heartburn $[29,30]$. That is why all data refer to typical reflux symptoms but not to a real GERD disease; in order to identify that, a sophisticated medical check-up of every interviewee would be necessary which was not feasible in the existing survey circumstances [31].

In addition to a descriptive analysis of the data a statistical analysis was done regarding treatment decisions of patients. In detail, three binary-logistic based regressionestimations were calculated:

1. Estimation of a dependent variable representing the general treatment decision of patients: no treatment versus treatment: The estimates show whether any variables influence the probability that a person decided to treat the reflux symptoms in any way or not.

2. Estimation of a dependent variable representing the fact whether a physician was visited: The estimates show whether any variables influence the probability that a person decided to visit a physician.

3. Estimation of a dependent variable representing the fact whether a specialist was visited: The estimates show whether any variables influence the probability that a person decided to visit a specialist.

\section{RESULTS}

\section{Reflux Incidence and Frequency/Severity of Symptoms}

Approximately $50.3 \%$ of the persons interviewed, 952 of 1,852 , have personally experienced reflux. Approximately $20.9 \%, 387$ of the interviewees, suffered from reflux symptoms during the 4 weeks prior to the interview (Fig. 1). The symptoms arose in different frequencies and different levels of severity. The severity of reflux symptoms for respondents

Table 1. Baseline Characteristics of the Sample

\begin{tabular}{|l|l|c|}
\hline Number of the Interviewed Persons & Persons & 1,892 \\
\hline Gender: Male & Persons/proportion in \% & $937 / 49.5 \%$ \\
\hline Gender: female & Persons/proportion in $\%$ & $955 / 50.5 \%$ \\
\hline Age & Mean/standard deviation & $46.8 / 16.3$ \\
\hline Winkler-social state index & Mean/standard deviation & $9.7 / 3.9$ \\
\hline Compulsory health insurance & Persons/proportion in $\%$ & $1,536 / 81.2 \%$ \\
\hline Compulsory health insurance + additional private insurance & Persons/proportion in $\%$ & $142 / 7.5 \%$ \\
\hline Private health insurance & Persons/proportion in $\%$ & $212 / 11.2 \%$ \\
\hline No health insurance & Persons/proportion in $\%$ & $2 / 0.1 \%$ \\
\hline
\end{tabular}




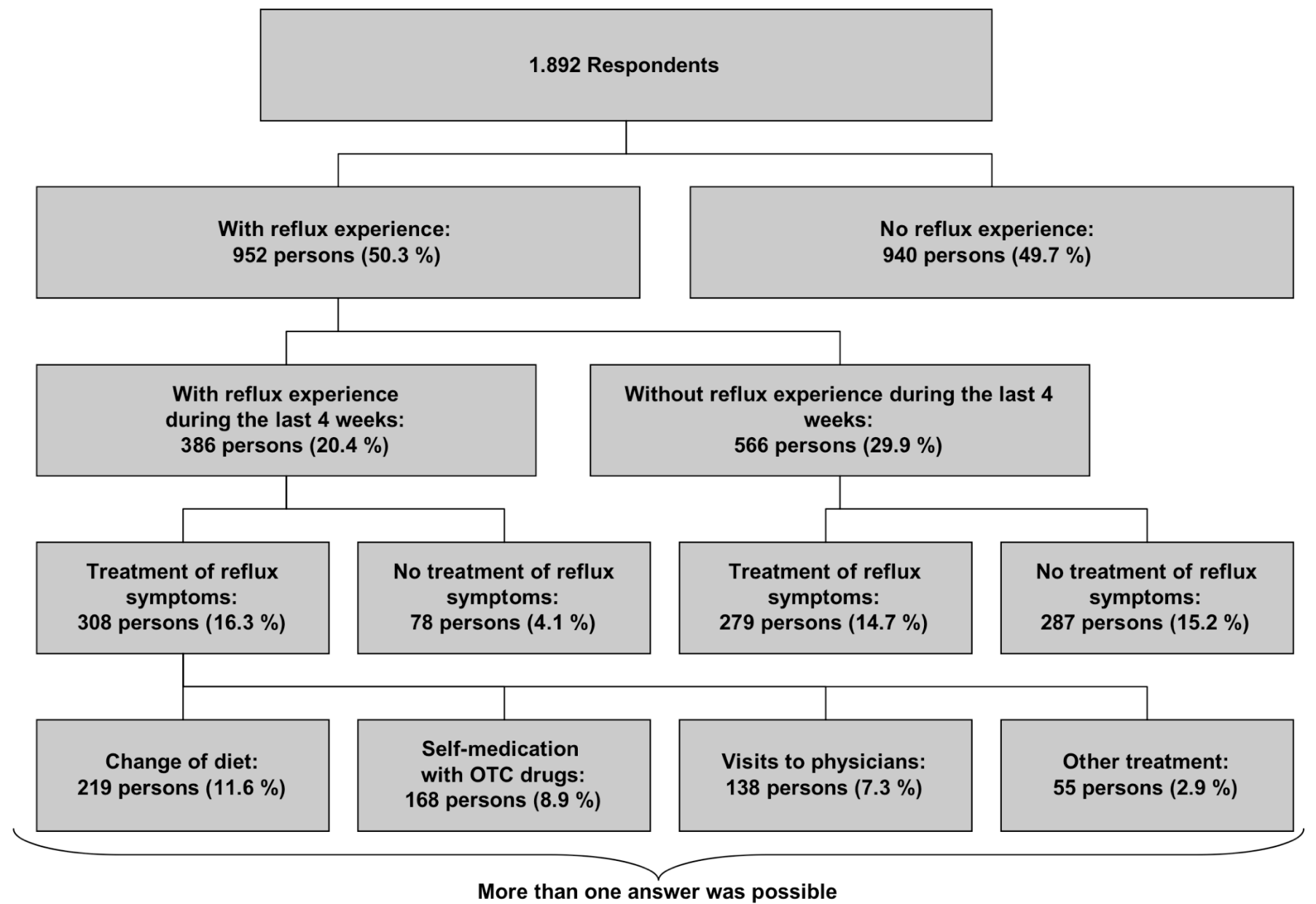

Fig. (1). Sample Structure: Reflux incidence and main treatment alternatives.

experiencing reflux was determined by means of five criteria which represent the most widely accepted symptoms of reflux [13]:

- $\quad$ frequency of reflux symptoms like heartburn or acid regurgitation,

- intensity of pain,

- change of eating habits,

- $\quad$ sleeping disorders, and

- $\quad$ absence from work (employed persons) or days with significant limitations in conducting their daily business (non-employed persons) because of reflux.

The answers of the respondents show that with the exception of the criterion lack of work/limited days, it can be concluded that at least $5-7 \%$ of the population suffers from acute reflux symptoms with a high level of severity. This result is confirmed by the distribution of a severity score (Fig. 2): For 123 of the interviewees $(6.5 \%)$, a severity score of more than 10 was calculated showing a far above-average severity of reflux symptoms. Regression estimates showed that sociodemographic variables do not explain the appearance and the severity of reflux symptoms: Age alone exerts a minor significant positive impact on the probability of the appearance of reflux symptoms.

\section{Treatment of Reflux Symptoms}

The 952 persons who had personally experienced reflux were asked about their corresponding treatment decisions (Fig. 1). The aim of these questions was to detect and - at least partly - to explain these decisions.

Fig. (1) also shows that approximately $80 \%$ of the interviewees with acute reflux experience (reflux symptoms occurring in the four weeks preceding the interview) treat their symptoms. Due to this fact it is clear that most sufferers acknowledge the need for treatment. Moreover, more than $50 \%$ of the "acute reflux symptoms subgroup" change their diet. Approximately $43 \%$ of respondents of this subgroup were taking OTC drugs whereas $36 \%$ of them had already consulted a physician. More than one answer was possible.

All in all 201 of the interviewees - 138 with reflux symptoms during the 4 weeks preceding the survey, and 63 respondents with symptoms lying further into the past- visited a physician because of their symptoms. That means that about $10.6 \%$ of the interviewees in the whole sample have already visited a physician because of reflux. The average person in this subgroup waited 8 months until taking the decision to make the visit; on average women waited 7.5 months and men waited 8.3 months. 


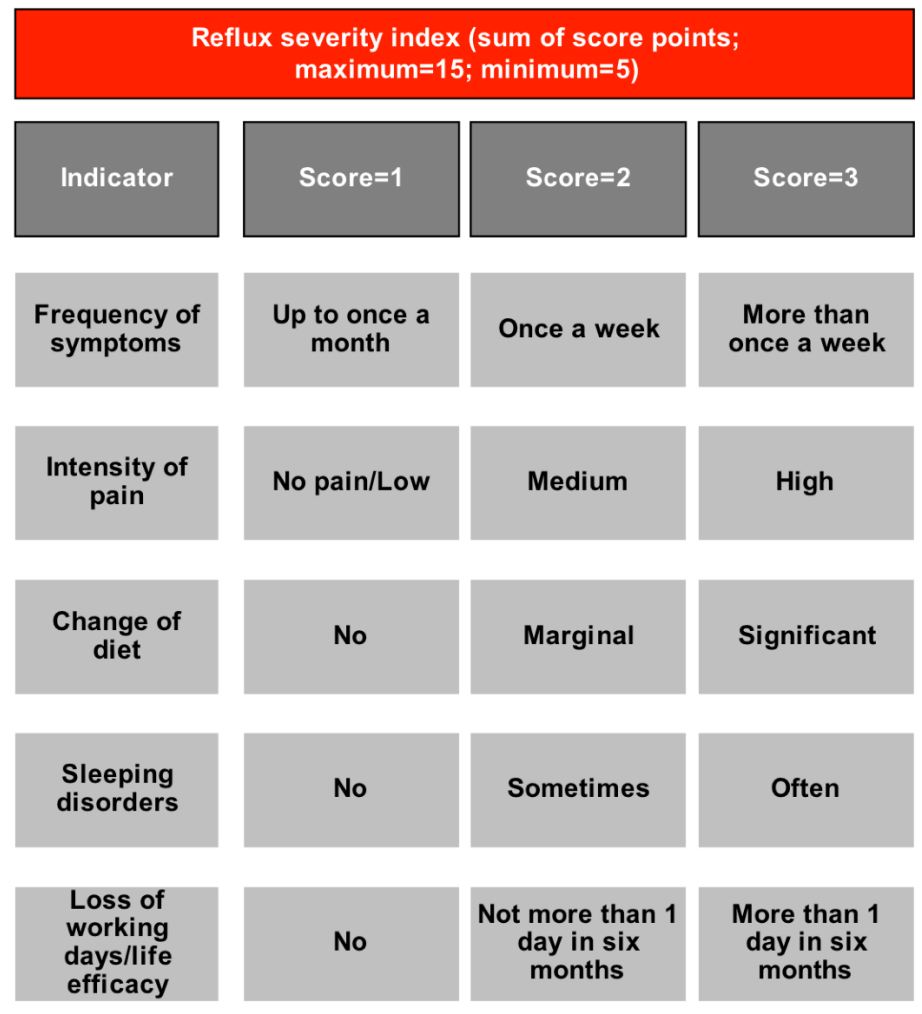

Distribution of the reflux severity score (952 interviewees with reflux experience)

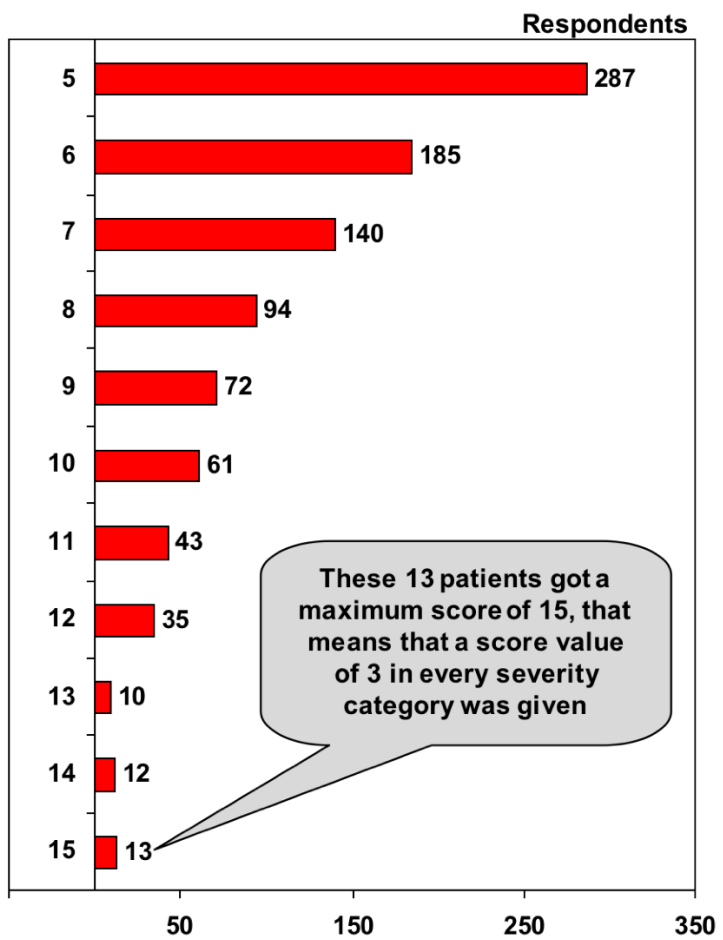

Fig. (2). Distribution of the reflux severity score.

201 respondents visited a physician

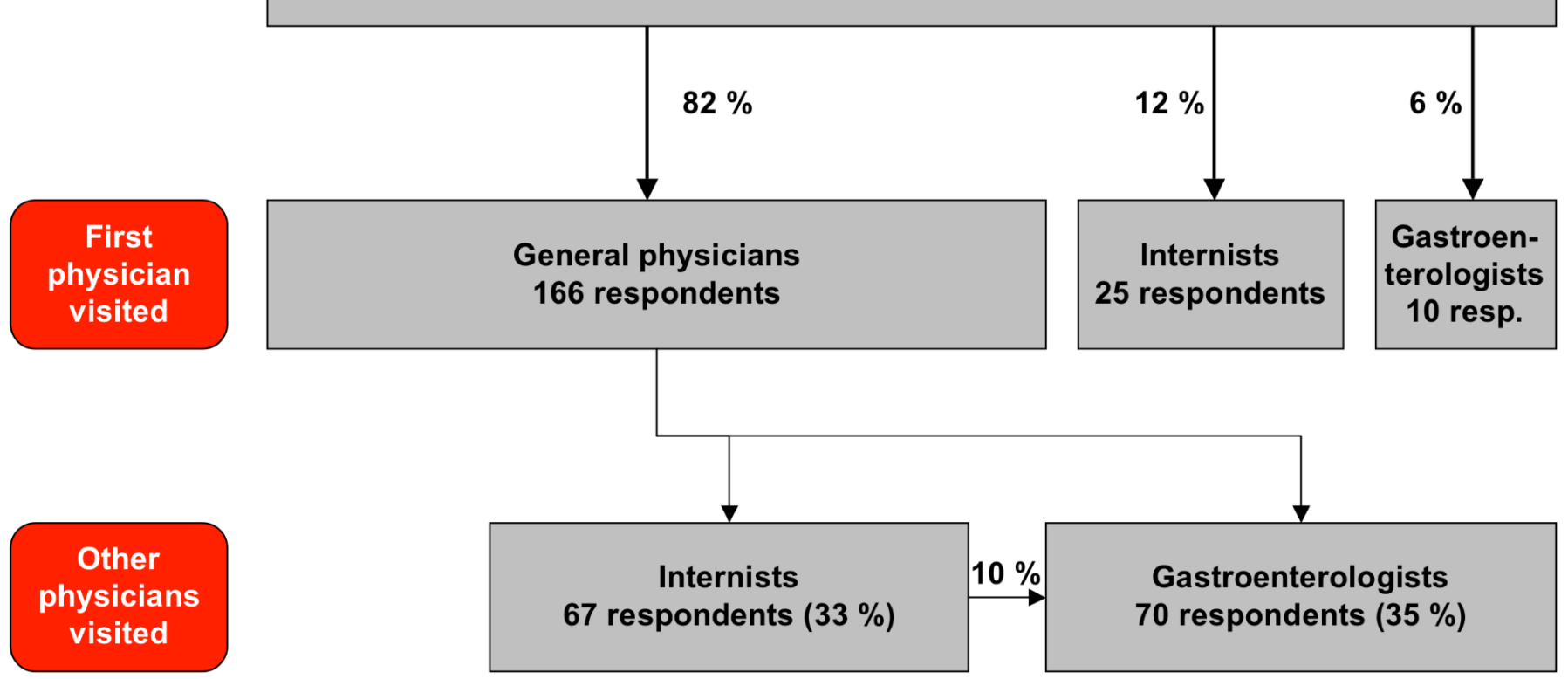

Fig. (3). Reflux treatment by physicians: Choice pathways of reflux patients.

Fig. (3) shows the typical choice pathways of respondents who had visited a physician because of reflux problems: approximately $82 \%$ of them visited a general practitioner in the first instance. Approximately $12 \%$ visited an internist, a more specialized physician for internal medi- cine, immediately, whereas approximately $6 \%$ chose to visit a gastroenterologist first. These data support the conclusion that general practitioners play a central role in the first treatment of reflux symptoms. However, during a treatment episode, the majority of patients are transferred to a specialist 
Table 2. Regression-Estimates for Reflux Treatment Decisions

\begin{tabular}{|c|c|c|c|c|c|c|}
\hline \multirow[t]{2}{*}{ Variables } & \multicolumn{2}{|c|}{$\begin{array}{c}\text { Dependent Variable: No } \\
\text { Treatment of Symptoms } \\
\text { (Binary Logit-Model, n=952) }\end{array}$} & \multicolumn{2}{|c|}{$\begin{array}{c}\text { Dependent Variable: } \\
\text { Consultation of a Physician } \\
\text { (Binary Logit-Model, } n=952 \text { ) }\end{array}$} & \multicolumn{2}{|c|}{$\begin{array}{c}\text { Dependent Variable: } \\
\text { Consultation of a Specialist } \\
\text { (Binary Logit-Model, } \mathbf{n}=\mathbf{2 0 1} \text { ) }\end{array}$} \\
\hline & Variable & $P$ & Variable & $\boldsymbol{P}$ & Variable & $p$ \\
\hline Constant & 5,086 & $<0,01$ & $-6,561$ & $<0,01$ & $-2,648$ & $<0,01$ \\
\hline Age & $-0,025$ & $<0,01$ & 0,026 & $<0,01$ & 0,032 & $<0,01$ \\
\hline Social state (Winkler-index) & $-0,032$ & 0,346 & 0,002 & 0,556 & 0,059 & 0,076 \\
\hline Gender $(1=$ male; $2=$ female $)$ & $-0,446$ & $<0,01$ & 0,096 & 0,376 & 0,061 & 0,224 \\
\hline Health insurance status & $-0,117$ & 0,107 & 0,080 & 0,381 & $-0,301$ & 0,691 \\
\hline Severity of reflux symptoms (score 1-15) & $-0,474$ & $<0,01$ & 0,450 & $<0,01$ & 0,108 & $<0,05$ \\
\hline Quality of the regres-sion estimate & \multicolumn{2}{|c|}{$\mathrm{R}^{2}(\mathrm{Cox})=0,216$} & \multicolumn{2}{|c|}{$\mathrm{R}^{2}(\mathrm{Cox})=0,214$} & \multicolumn{2}{|c|}{$\mathrm{R}^{2}(\operatorname{Cox})=0,014$} \\
\hline
\end{tabular}

sooner or later. The importance of general practitioners at the beginning of a reflux-treatment episode was also illustrated by another fact: approximately $90.5 \%$ of patients who had not consulted a physician up to the time of the survey would choose to visit a general practitioner first at such time as they changed their minds about the need for medical help. This group of respondents mentioned strong reflux-pain $(91.0 \%)$ followed by a lack of ability to work (68.7\%) and sleeping disorders $(55.9 \%)$ as likely grounds for visiting a physician in the future.

On what does the choice of a mode of reflux-treatment depend? The sample included in the statistical estimates answering this question consisted of interviewees who have personally experienced reflux symptoms. The results of these estimations are shown in Table 2.

The estimations show that patients' historical treatment decisions can be explained with a good level of confidence:

- $\quad$ The most important parameter for the decision to treat reflux symptoms or not and - in case where treatment is seen as necessary - to visit a physician is the reflux symptoms severity (measured by the severity score). Only $6.5 \%$ of respondents with severe symptoms (score $>10$ ) did not treat their symptoms at all. Moreover, this group has a significantly higher probability of consulting a physician (Table 2)

- $\quad$ Age of respondents has its own significant impact in all three estimates (Table 2). Elderly people are less likely to abandon any treatment. Furthermore, they are more likely to consult a general practitioner or a specialist.

- $\quad$ For a person's general treatment decision, gender has a very limited power of explanation. While women are less likely to decide to abandon any treatment, gender has no relevance in the decision to visit a physician or not.

- It is important and somewhat surprising that neither a person's social status nor his health insurance coverage explain the treatment decisions (Table 2).

\section{DISCUSSION}

Limitations: The survey analyzes questions concerning the prevalence of reflux in Germany and patient's treatment decisions. Interviews were done face to face "on the street" in 6 German cities. Because of specific guidelines for all interviewers, the analyzed sample is representative for Germany concerning age, sex, and social status. However, it is not solely representative because of a possible geographical bias.

Based on German-wide date, obviously some persons did not answer the question concerning their insurance status (not basic insurance, but additional insurances) correctly. So it cannot be entirely excluded that some results concerning the influence of the insurance status on patients' behaviour are biased.

Prevalence of reflux symptoms: This survey shows that approximately $50 \%$ of the respondents have experienced reflux symptoms, whereby approximately $21 \%$ suffer from acute symptoms (as established by incidents of reflux that occurred up to 4 weeks prior to the survey). Compared to earlier studies, that is a comparatively high reflux prevalence $[22,24-25]$. Part of the explanation may be that the prevalence of reflux is increasing in Germany. On the other hand, data in this paper are based on face-to-face interviews. Most other existing surveys are based on answers on written questionnaires or phone interviews.

Sociodemographic/socioeconomic factors and reflux symptoms prevalence: Sociodemographic factors - with the exception of the age of interviewees - do not exert a significant influence on the likelihood of reflux or their severity. That is also true for the gender of respondents. This finding confirms the results of recent surveys [22-25].

In this study, socioeconomic status of the respondents was measured by a special social status index depending on education, professional status and household income. Following the widespread opinion about the relationship between socioeconomic status and health status one would expect a negative relationship between the individual prevalence of reflux symptoms and socioeconomic status of a person [35-37]. Interestingly, no such relationship could be found. Obviously, variables which reflect the individual health situation like the body-mass-index or genetic factors as well as a possible consumption of alcohol and nicotine would seem to be likely to be more important in this respect [30-32]. However, in a face-to-face interview "on the street" these data cannot be collected in a manner that ensures a 
sufficient level of quality, so the importance of these factors was not investigated. Whether the reported results can be explained by the calculated Winkler-social state index or whether reflux does not depend on socioeconomic variables at all remains open for future research.

Treatment of reflux symptoms: Up to now, no survey dealing with the German population did analyze treatment decisions of reflux patients. It could be shown that most patients with reflux symptoms treat their symptoms. Only $20 \%$ of the respondents with acute reflux symptoms do not treat them at all. Nevertheless, as many as $40 \%$ of this patient subgroup did not visit a physician up to the time of the survey. Analyzing the "really severe" cases of reflux symptoms (score $>13$ ) this number reduces to $10 \%$.

Younger interviewees, men and persons with a lower reflux-severity score are more likely than other groups to decide to abandon any treatment or physician's consultations. Part of the explanation may be co-morbidities in elderly people, and guidelines which foster the preventive medical checkups done by specialists. Whether it is detrimental from a health policy perspective that younger interviewees and men abandon any treatment with a higher probability has to be evaluated from a medical perspective.
In cases where treatment is necessary, from the perspective of the sufferer, dieting and self-medication with OTC drugs are dominant. The decision to consult a physician depends - unsurprisingly - on the severity of symptoms and the age of a person. With respect to patients' treatment choice pathways, general practitioners play a central role as the first point of contact with medical personnel. After initial treatment, most of patients are transferred to a specialist. Patients wait a comparably long time before visiting a physician.

Analyzing a person's treatment decisions one would expect - again - a relationship between socioeconomic status/health insurance coverage and individual treatment decisions. However, all regression estimates show that there is no evidence for this relationship. That means that the decision to treat reflux symptoms in general and to consult a general practitioner/specialist in detail do not depend on the social status of a person or his health insurance coverage. Obviously, socioeconomic and demographic factors might have different effects in other countries with other health care systems. Nevertheless, at least in relation to reflux symptoms, there is no evidence for the existence of a medical system in Germany that favours persons with a higher social status. Whether this result remains true in future is a completely different question.

\section{Appendix A: Questionnaire (I)}
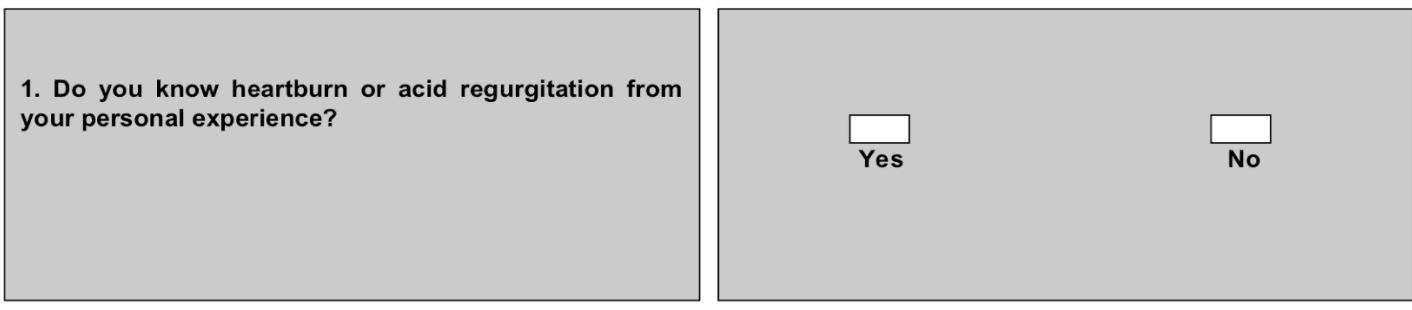

\section{Appendix A: Questionnaire (II)}
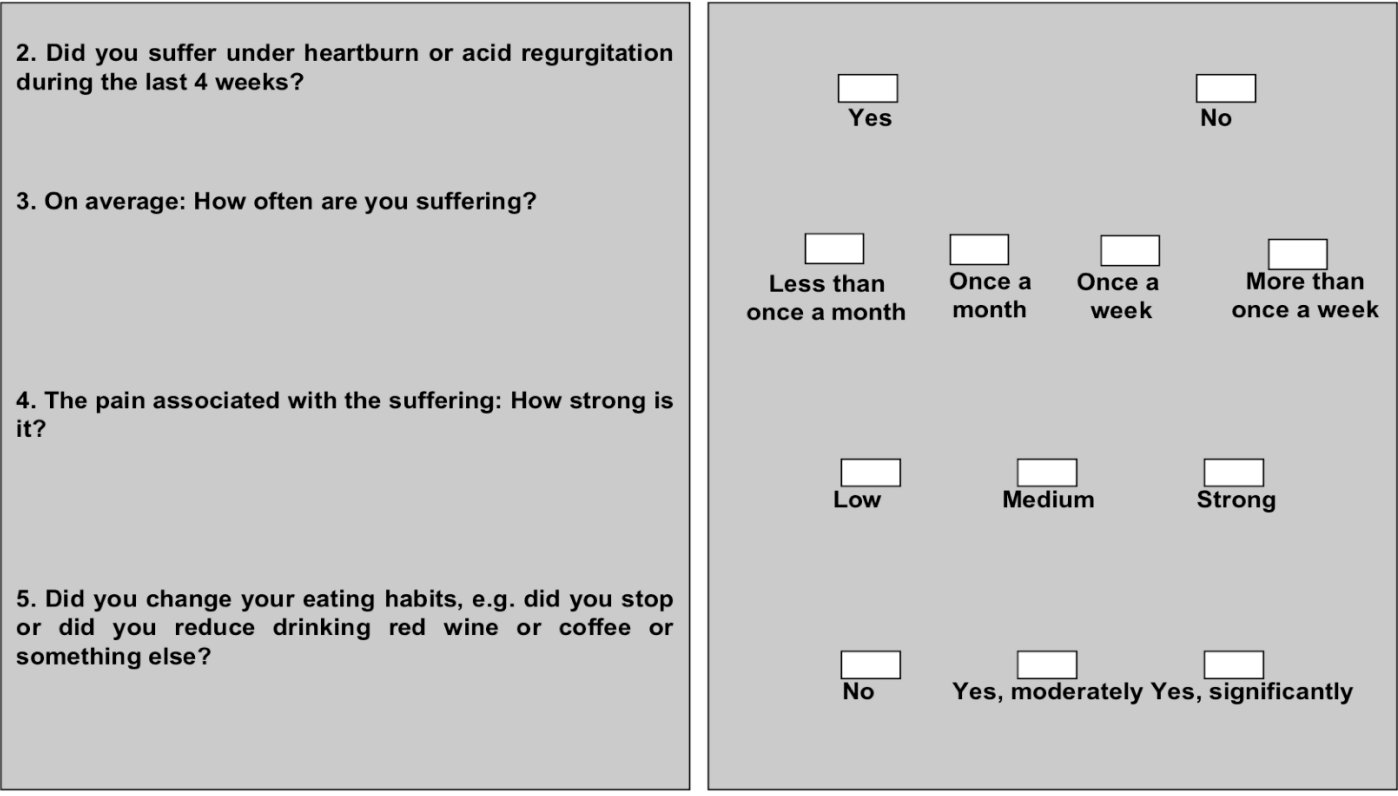


\section{Appendix A: Questionnaire (III)}
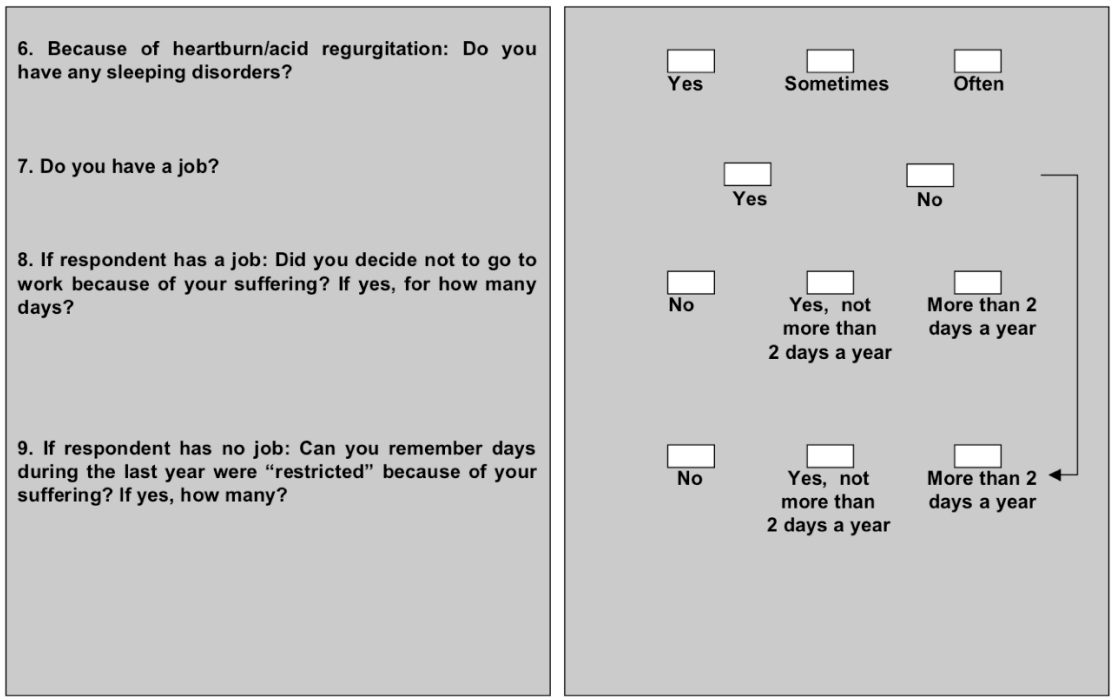

\section{Appendix A: Questionnaire (IV)}
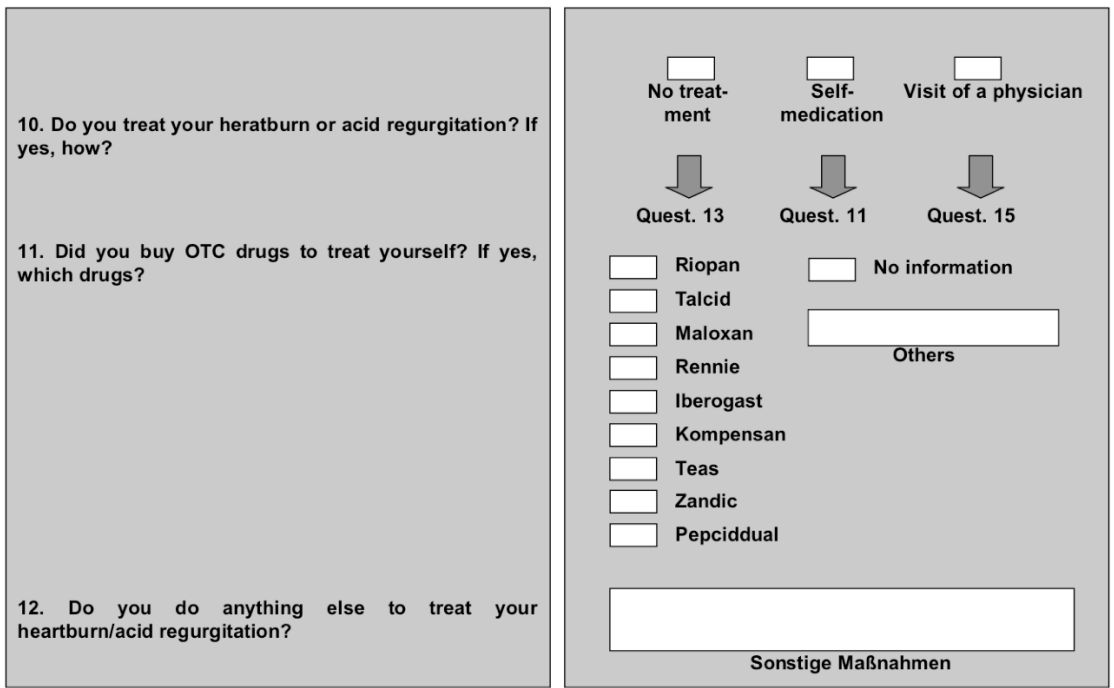

Appendix A: Questionnaire (V)
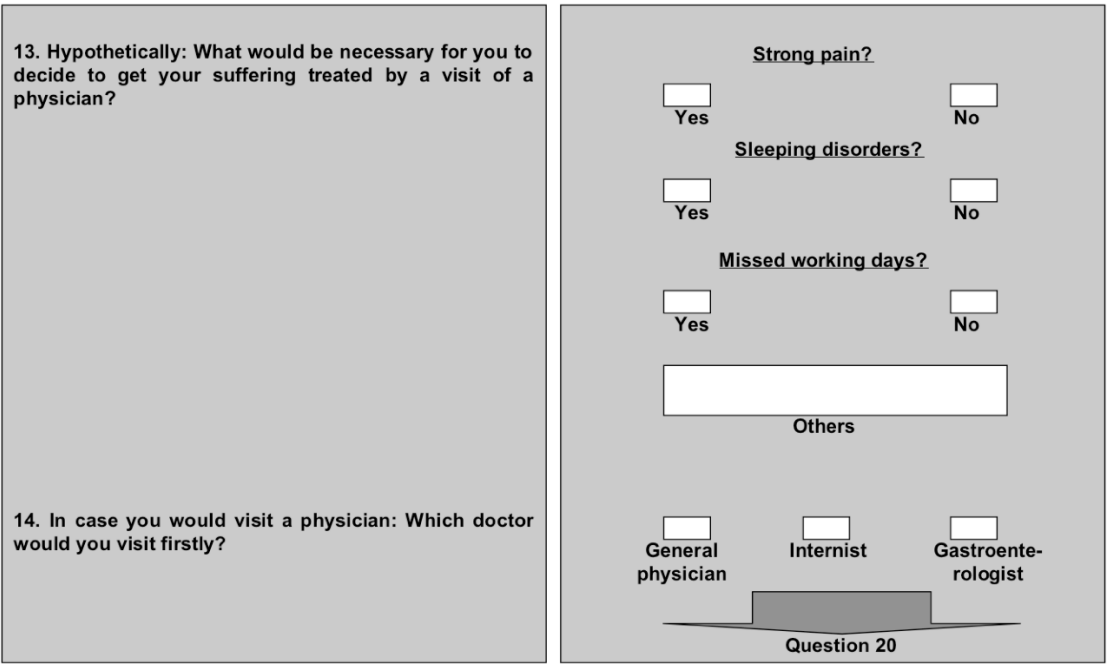


\section{Appendix A: Questionnaire (VI)}

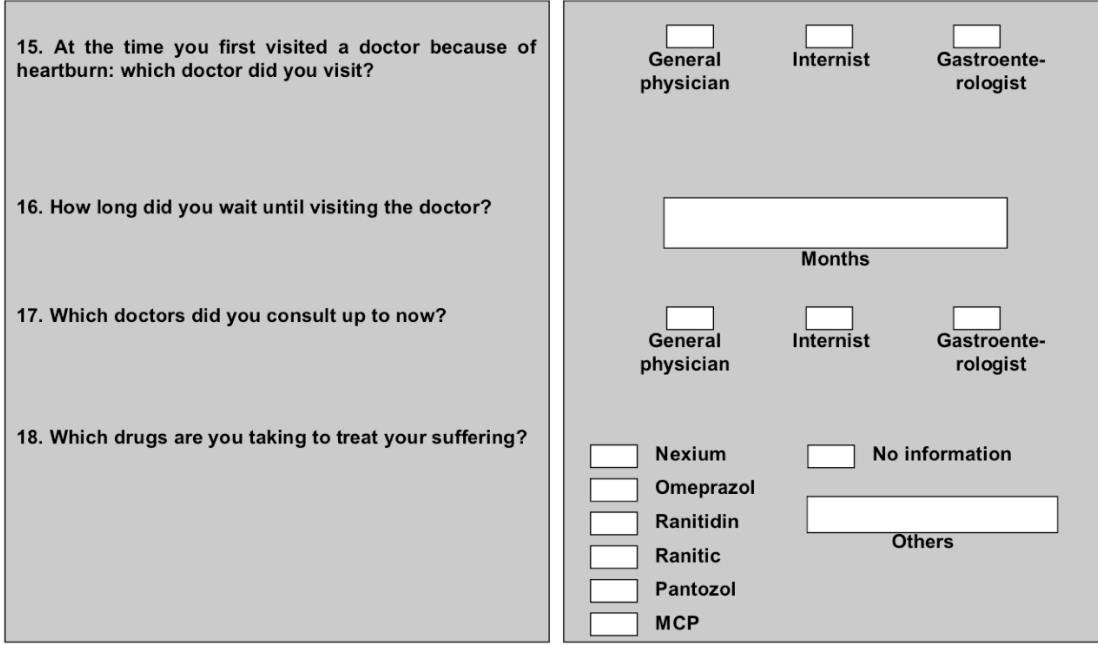

Appendix A: Questionnaire (VII)

At the end of the interview, we would like to ask so
personal questions.
19. How old are you?
20. What education do you have (german scale)?

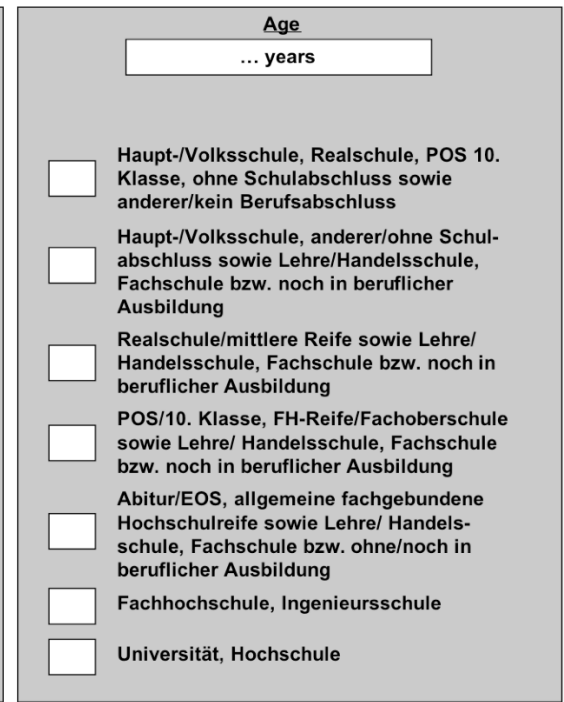

Appendix A: Questionnaire (VIII)
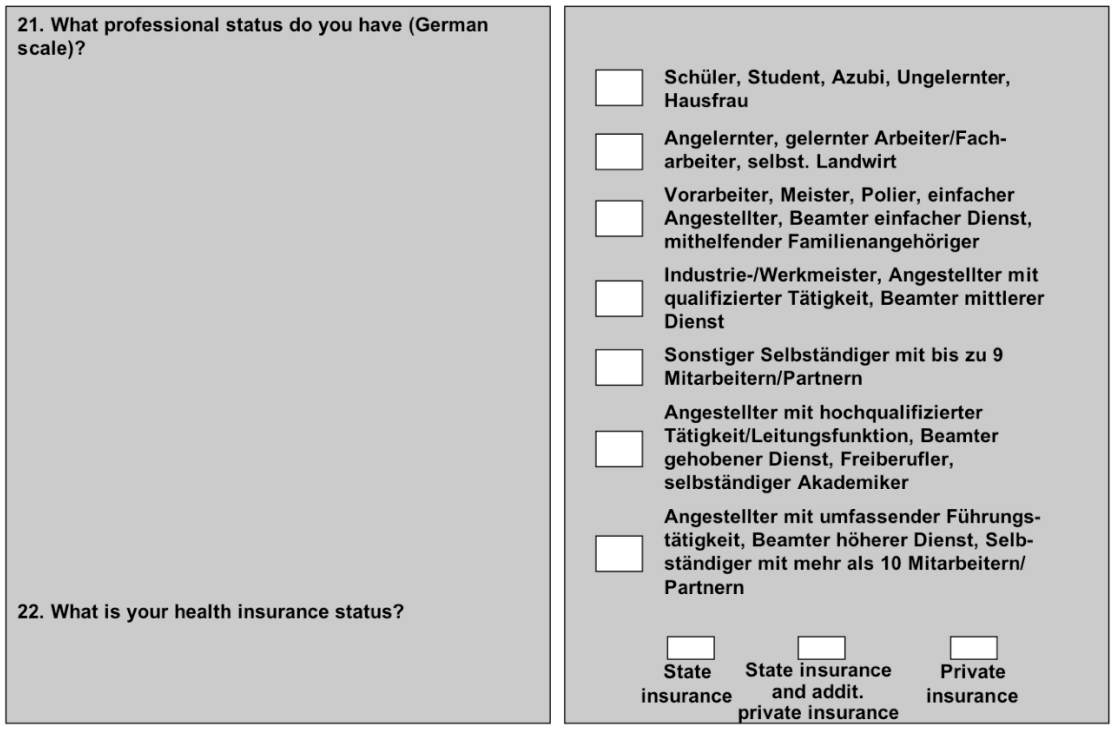
Appendix A: Questionnaire (IX)

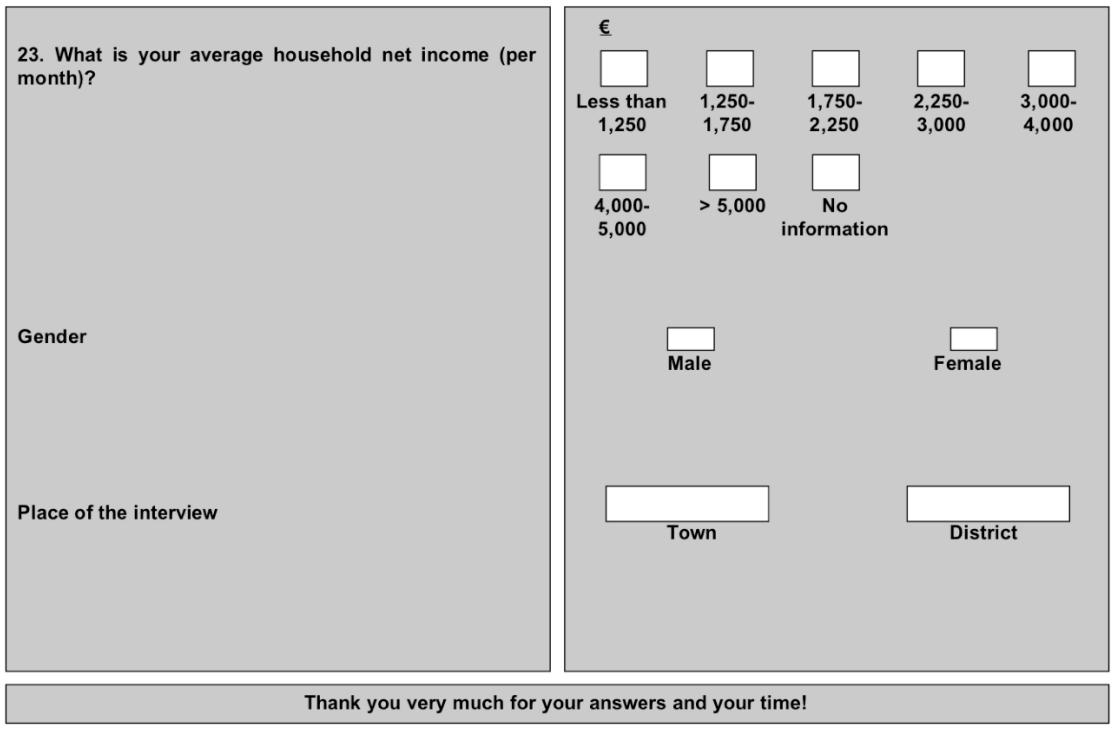

\section{Appendix B: Regional structure of the sample}
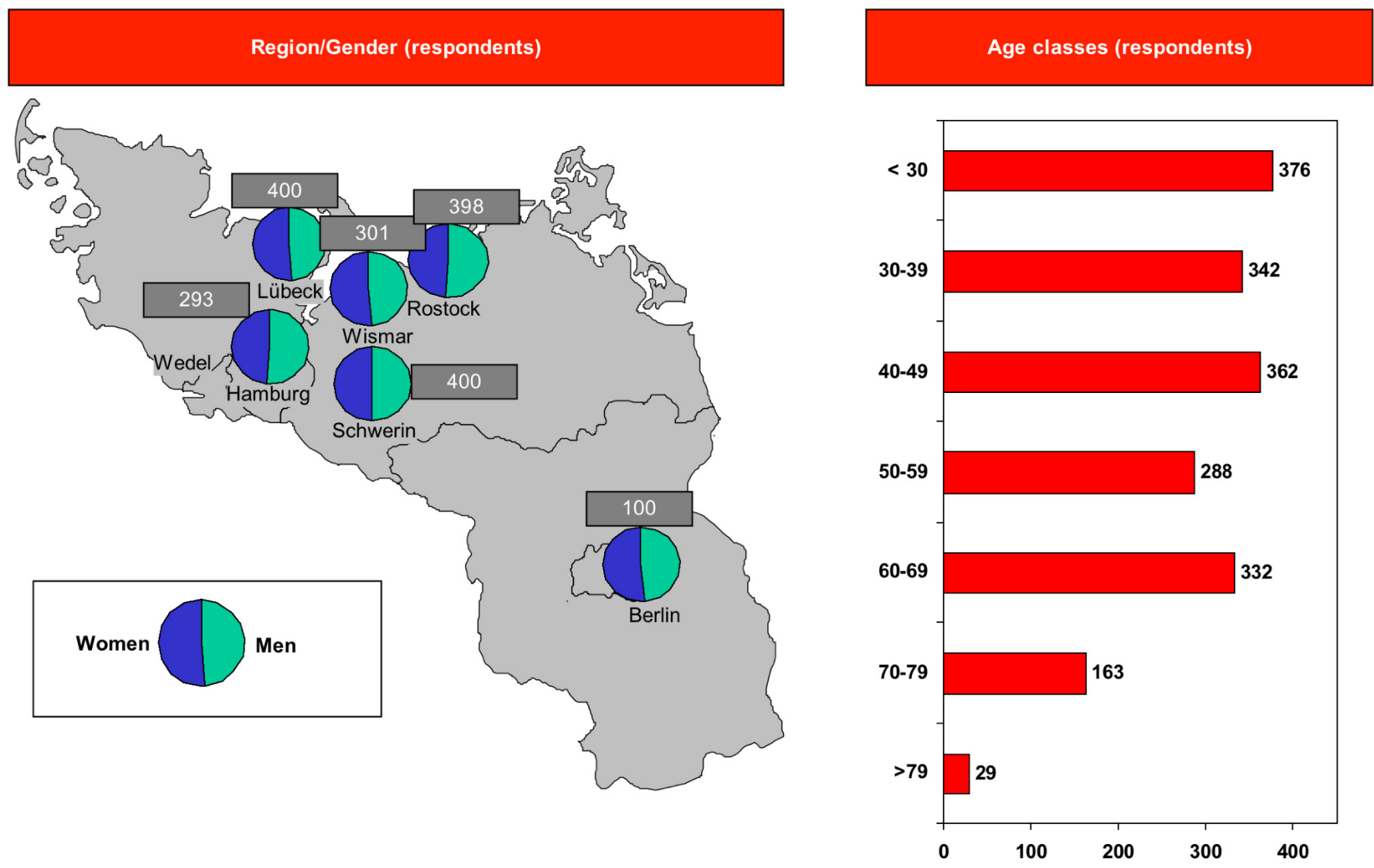


\section{ACKNOWLEDGEMENTS}

The survey was supported by a unrestricted research grant from Astra Zeneca. The authors would like to thank the Hochschule Wismar, University of Technology, Business and Design, for its support. Moreover, they would like to thank four referees for their very helpful comments.

\section{REFERENCES}

[1] Nebel OT, Fornes MF, Castell DO. Symptomatic gastroesophageal reflux: incidence and precipitating factors. Am J Dig Dis 1976; 21: 953-956.

[2] Gallup A. Organization national survey. Heartburn across America. Princeton, NJ: The Gallup Organization, 1988.

[3] Spechler SJ. Epidemiology and natural history of gastrooesophageal reflux disease. Digestion 1992; 51 (Suppl 1): 24-29.

[4] Galmiche JP, Bruley V. Symptoms and disease severity in gastroesophageal reflux disease. Scand J Gastroenterol 1994; 29: 62-68.

[5] Petersen $\mathrm{H}$. The prevalence of gastro-oesophageal reflux disease. Scand J Gastroenterol 1995; 30: 5-6.

[6] Isolauri J, Laippala P. Prevalence of symptoms suggestive of gastroesophageal reflux disease in an adult population. Ann Med 1995; 27: 67-70.

[7] Locke GR, Talley NJ, Fett SL, Zinsmeister AR, Melton LJ 3rd. Prevalence and clinical spectrum of gastroesophageal reflux: a population-based study in Olmstead Country. Minnesota Gastroenterol 1997; 112: 1448-1556.

[8] Frank L, Kleinman L, Ganoczy D. Upper gastrointestinal symptoms in North America. Prevalence and relationship to healthcare utilizaton and quality of life. Dig Dis Sci 2000; 45: 809-818.

[9] Avidan B, Sonnenberg A, Schnell TG, Sontag SJ. Risk factors for erosive reflux esophagitis: a case-control study. Am J Gastroenterol 2001; 96: 41-46.

[10] Armstrong D, Jones R. Prevalence and understanding of reflux symptoms and GERD in five European countries. Gastroenterology 2001; 120 (Suppl 1): A 427.

[11] Shaw MJ, Talley NJ, Beebe TJ. Initial validation of a diagnostic questionnaire for gastroesophageal reflux disease. Am J Gastroenteroly $2001 ; 96: 52-57$.

[12] Manterola C, Munoz S, Grande L, Bustos L. Initial validation of a questionnaire for detecting gastroesophageal reflux disease in epidemiological studies. J Clin Epidemiol 2002; 55: 1041-1045.

[13] Dent J. Review article: from 1906 to 2006 - a century of major evolution of understanding of gastro-oesophageal reflux disease. Aliment Pharmacol Ther 2006; 24: 1269-1281.

[14] Yang SY, Lee OY, Bak YT, et al. Prevalence of Gastroesophageal Reflux Disease Symtoms and Uninvestigated Dysepsia in Korea: A Population-Based Study. Dig Dis Sci 2008; 53: 188-93.

[15] Ehsani MJ, Maleki I, Mohammadzadeh F, Mashayekh A. Epidemiology of gastroesophageal reflux disease in Tehran. Iran. J Gastroenterol Hepatol 2007; 22: 1419-1422.

[16] Nouraie M, Razjouyan H, Assady M, Malekzadeh R, NasseriMoghaddam S. Epidemiology of gastroesophageal reflux symptoms in Teheran, Iran: a population-based telephone survey. Arch Iran Med 2007; 10: 289-294.

[17] Rey E, Moreno Elola-Olaso C, Rodriguez Artalejo F, Diaz-Rubio M. Impact of gastroesophageal reflux symptoms on health resource usage and work absenteeism in Spain. Rev Esp Enferm Dig 2006; 98: 518-526.

[18] Kulig M, Leodolter A, Vieth M. Quality of life in relation to symptoms in patients with gastro-oesophageal reflux disease - an analysis based on the ProGERD initiative. Aliment Pharmacol Ther 2003; 18: 767-776.

[19] Kulig M, Nocon M, Vieth M, et al. Risk factors of gastroesophageal reflux disease: methodology and first epidemiological results of the ProGERD study. J Clin Epidemiol 2004; 57: 580-589.

[20] Bardhan KD, Royston C, Nayyar AK. Reflux rising! A disease in evolution? Gut 2000; 46 (Suppl 2): A 91.

[21] Serag HB. Time trends of gastroesophageal reflux disease: a systematic review. Clin Gastroenterol Hepatol 2007; 5: 17-26.

[22] Armstrong D, Jones R. Prevalence and understanding of reflux symptoms and GERD in five European countries. Gastroenterology 2001; 120 (Suppl 1): A 427.

[23] Hollenz M, Stolte M, Labenz J. Prävelenz der Refluxkrankheit in einer Allgemeinpraxis. Dtsch Med Wochenschr 2002; 127: 10071012.

[24] Bollschweiler E, Knoppe K, Wolfgarten E, Hölscher A H. Prevalence of Reflux Symptoms in the General Population of Cologne. Z Gastroenterol 2007; 45: 177-181.

[25] Nocon M, Keil T, Willich SN. Prevalence and sociodemographics of reflux symptoms in Germany-results from a national survey. Aliment Pharmacol Ther 2006; 23: 1601-1605.

[26] U.S. Census Bureau, International Data Base.

[27] Winkler J, Stolzenberg H. Der Sozialschichtindex im BundesGesundheitssurvey. Gesundheitswesen 1999; 61(Sonderheft 2): S178-S183.

[28] Verband der privaten Krankenversicherung 2004: number of insured people in Germany: 8.259 Mill. private insured people; 16.139 Mill. compulsary insured people with an additional private insurance.

[29] Nebel OT, Fornes MF, Castell DO. Symptomatic gastroesophageal reflux: incidence and precipitating factors. Dig Dis 1976; 21: 953956.

[30] Klauser AG, Schindlbeck NE, Müller-Lissner. Symptoms in gastrooesophageal reflux disease. Lancet 1990; 335: 205-208.

[31] Tutuian R. Update in the diagnosis of gastroesophageal reflux disease. J Gastrointestin Liver Dis 2006; 15: 243-247.

[32] Trudgill NJ, Kapur KC, Riley SA. Familial clustering of reflux symptoms. Am J Gastroenterol 1999; 94: 1172-1178.

[33] Corley DA, Kubo A. Body mass index and gastroesophageal reflux disease: a systematic review and meta-analysis. Am J Gastroenterol 2006; 101: 2619-2628.

[34] Nocon M, Labenz J, Eillich SN. Lifestyle factors and symptoms of gastro-oesophageal reflux - a population-based study. Aliment Pharmacol Ther 2006; 23: 169-174.

[35] Locke GR, Talley NJ, Fett SL, Zinsmeister AR, Melton LJ. Risk factors associated with symptoms of gastroesophageal reflux. Am J Med 1999; 106: 642-649.

[36] Cozier YC, Palmer JR, Horton RJ, Fredman L, Wise LA, Rosenberg L. Relation between neighborhood median housing value and hypertension risk among black women in the United States. Am J Public Health 2007; 97: 718-724.

[37] Murray CJ, Kulkarni S, Ezzati M. Eight Americas: new perspectives on U.S. health disparities. Am J Prev Med 2005; 29: 4-10. 